\title{
Multiple Perforations of the Small Intestine during Systemic
} Sclerosis

\author{
Salem Bouomrani ${ }^{1,2, *}$, Sawssan BenTeber ${ }^{1,2}$, Ines Masmoudi ${ }^{1,2}$, Marwa Ghribi ${ }^{1,2}$ \\ ${ }^{l}$ Department of Internal medicine, Military Hospital of Gabes, Gabes, Tunisia \\ ${ }^{2}$ Sfax Faculty of Medicine, University of Sfax, Tunisia
}

*Corresponding Author: Salem Bouomrani, Department of Internal medicine, Military Hospital of Gabes, Gabes, TunisiaSfax Faculty of Medicine, University of Sfax, Tunisia, Email: salembouomrani@yahoo.fr

\begin{abstract}
Systemic sclerosis (SS) or scleroderma is a very rare systemic connective tissue disease.
Intestinal involvement is reported in 40 to $60 \%$ of cases of SS, and is by far dominated by intestinal hypo motility, malabsorption syndrome, and pseudo-obstructions. Intestinal perforation remains exceptional, dominates particularly in the colon, and is associated with a poor prognosis (6-12\% of the overall mortality from this connective tissue disease).
\end{abstract}

We report the original observation of SS complicated by multiple perforations of the small intestine in 28year-old Tunisian woman.

Keywords: perforation, small intestine, systemic sclerosis, scleroderma.

\section{INTRODUCTION}

Systemic sclerosis (SS) or scleroderma is a very rare systemic connective tissue disease [1,2]: prevalence estimated at 30 to 443 per million population [3].

It is characterized by a fibroblastic proliferation with accumulation of dense collagen in the connective tissue, a diffuse microangiopathy, and an immunological disorder [1,2]: presence of anti-nuclear auto-antibodies, of which the most specific of SS are anti-topoisomerase I, anti-centromere, and anti-RNA polymerase III antibodies according to the clinical form of SS[4,5].

Clinical manifestations are dominated by cutaneous, articular, pulmonary, gastro esophageal, cardiovascular, and renal involvement [1-3].

The digestive manifestations of this connective tissue disease can be seen in more than $90 \%$ of cases during the course of the disease [3,6]. All the structures of the digestive tract can be reached from the oral cavity to the anus [3,6,7]. Intestinal involvement is reported in 40 to $60 \%$ of cases, and is by far dominated by intestinal hypomotility, malabsorption syndrome, and pseudo-obstructions $[3,6]$. Intestinal perforation remains exceptional, dominates particularly in the colon, and is associated with a poor prognosis.

We report the original observation of SS complicated by multiple perforations of the small intestine.

\section{CASE REPORT}

28-year-old Tunisian woman, followed for two years for SS with skin (Figs. 1 and 2), esophageal, osteoarticular (Fig. 3), and cardiovascular involvement was hospitalized from the emergency department for acute abdominal pain worsening rapidly since the day before.

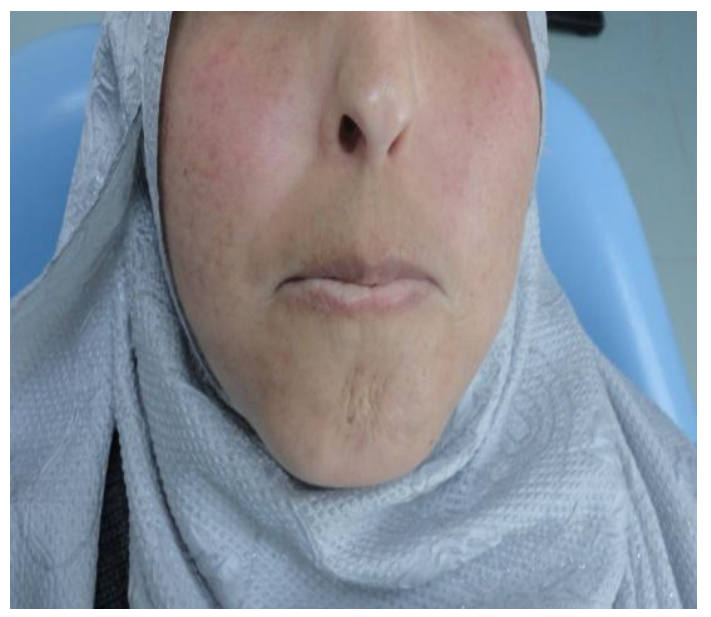

Fig1: Sclerodermic face. 


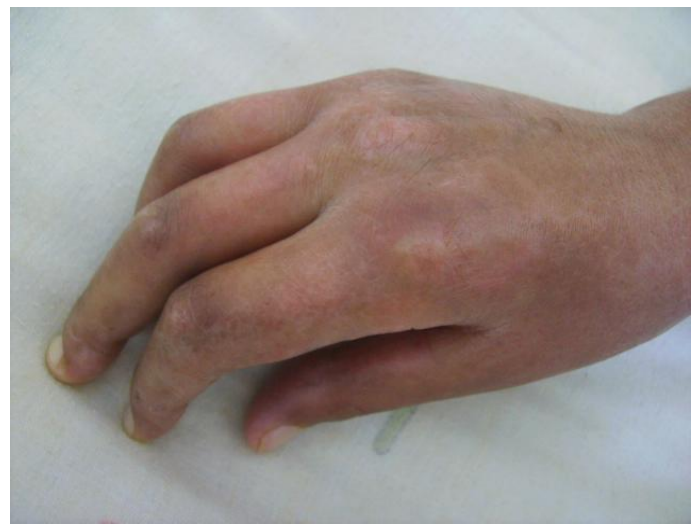

Fig2: sclerodactyly.

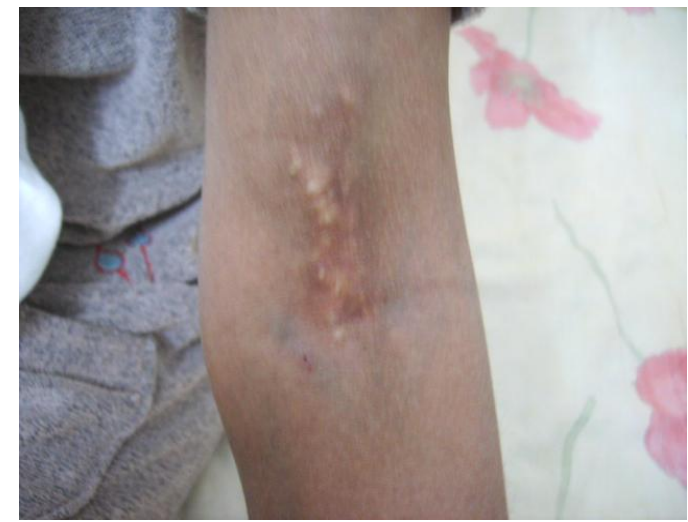

Fig3: Subcutaneous calcinosis of the left elbow

The somatic examination noted a feverish patient at $38.7^{\circ} \mathrm{C}$ with a hardened anterior abdominal wall, not depressible, and painful on palpation. Hemodynamic, respiratory, and neurological status were preserved.

Basic biological tests showed leukocytosis at $12800 / \mathrm{mm}^{3}$ with $80 \%$ of neutrophils, C-reactive protein at $49 \mathrm{mg} / \mathrm{l}$, and erythrocyte sedimentation rate at $52 \mathrm{~mm} / \mathrm{H} 1$. The other tests were within normal limits: hemoglobin, platelets, amylasemia, lipasemia, glycemia, calcemia, ionogram, troponin Ic, transaminases, and creatinine. The ECG and chest X-ray did not reveal any abnormalities.

The abdominal ultrasound showed minimal peritoneal effusion and dilated small bowel loops with thickened walls.

The patient was transferred to the surgical department for urgent surgery with the diagnosis of acute peritonitis.

Intraoperative exploration showed generalized peritonitis with false membranes, multiple punctate ulcers of the small intestine with multiple perforations. The colon was normal. An enlarged resection of the small intestine was performed and broad-spectrum antibiotic therapy was prescribed.
The histopathological examination showed multiple punctate perforations of the terminal ileum and jejunum covered with fibrinoleukocytic material, several superficial ulcers of the small intestinal mucosa with angiodysplasia, micovasculopathy, and diffuse fibrosis. No micro thrombosis, specific vasculitis, or granuloma was noted.

Anti-phospholipid, anti-cardiolipin, anti- $\beta$-2glycoprotein 1 ( $\beta 2 \mathrm{GP} 1)$, and anti-neutrophil cytoplasmic (ANCA) antibodies were negative. Likewise, no associated constitutional thrombophilia has been noted (normal levels of protein $\mathrm{C}$, protein $\mathrm{S}$, anti-thrombin III, and noctivated protein $\mathrm{C}$ resistance).

The subsequent course was favorable under systemic corticosteroids.

\section{DISCUSSION}

Gastrointestinal involvement is seen in more than $90 \%$ of cases of SS [3,6]. It mainly affects the esophagus: $90 \%$, the anus and rectum: 50$70 \%$, the stomach: $40-70 \%$, the colon: $10-50 \%$, and the small intestine: $40 \%$ [8].

It is the first sign revealing the disease in $10 \%$ of cases [3], and is responsible for $6-12 \%$ of the overall mortality from this connective tissue disease [3].

The main presentations of SS-specific intestinal involvement are: hypomotility, small intestinal bacterial overgrowth, malabsorption, chronic pseudo-obstruction syndrome, diarrhea, pneumatosisintestinalis, and bleeding by small intestinal telangiectasia/angiodysplasia $[3,9,10]$.

Severe forms of intestinal involvement, as for our patient, are seen only in $8 \%$ of cases [6]. Ulceration and perforation remain exceptional in the small intestine [11, 12]; they are particularly reported in the colon as a consequence of the classic "stercoral ulcers" [13-15].

The causal mechanism of these complications is intestinal neuropathy associated with progressive fibrosis of the intestinal myocytes as well as the micro-vasculopathy that characterizes this disease [12]. However, anecdotal cases of spontaneous intestinal perforation in sclerodermic patients have been reported [11].

\section{CONClusion}

The intestinal involvement during SS deserves to be known by health professionals given its important prognostic implications. 
Regular clinical and endoscopic screening is very useful for the early diagnosis and adequate management of this disorder, especially since it can remain completely asymptomatic.

\section{REFERENCES}

[1] Denton CP, Khanna D. Systemic sclerosis. Lancet. 2017; 390(10103):1685-1699.

[2] Soukup T, Veleta T. Systemic sclerosis in 2017. VnitrLek. Spring 2018;64(2):146-154.

[3] Frech TM, Mar D. Gastrointestinal and Hepatic Disease in Systemic Sclerosis. Rheum Dis Clin North Am. 2018; 44(1):15-28.

[4] Kuwana M. Circulating Anti-Nuclear Antibodies in Systemic Sclerosis: Utility in Diagnosis and Disease Subsetting. J Nippon Med Sch. 2017; 84(2):56-63.

[5] Sakkas LI, Simopoulou T, Katsiari C, Bogdanos D, Chikanza IC. Early systemic sclerosis-opportunities for treatment. Clin Rheumatol. 2015; 34(8):1327-31.

[6] Gyger G, Baron M. Systemic Sclerosis: Gastrointestinal Disease and Its Management. Rheum Dis Clin North Am. 2015; 41(3):45973.

[7] Bouomrani S, BelHadj R, Ben Khoud S, Béji M. Oral manifestations of systemic sclerosis. Pan Afr Med J. 2013; 16:114.

[8] Lidia Vera-Lastra O. Systemic sclerosis and the gastrointestinal tract. Diagnostic and therapeutic approach. ReumatolClin. 2006;2 (Suppl 3):S24-30.

[9] Sakkas LI, Simopoulou T, Daoussis D, Liossis $\mathrm{SN}$, Potamianos S. Intestinal Involvement in Systemic Sclerosis: A Clinical Review. Dig Dis Sci. 2018; 63(4):834-844.

[10] Marie I, Antonietti M, Houivet E, Hachulla E, Maunoury V, Bienvenu B, et al. Gastrointestinal mucosal abnormalities using videocapsule endoscopy in systemic sclerosis. Aliment Pharmacol Ther. 2014; 40(2):189-99.

[11] Battle WM, McLean GK, Brooks JJ, Herlinger $\mathrm{H}$, Trotman BW. Spontaneous perforation of the small intestine due to scleroderma. Dig Dis Sci. 1979; 24(1):80-4.

[12] Ebert EC, Ruggiero FM, Seibold JR. Intestinal perforation. A common complication of scleroderma. Dig Dis Sci. 1997; 42(3):549-53.

[13] Robinson JC, Teitelbaum SL. Stercoral ulceration and perforation of the sclerodermatous colon: report of two cases and review of the literature. Dis Colon Rectum. 1974; 17(5):622-32.

[14] Pialoux G, Mouly F, Cadranel JF, Fléjou JF, Marcellin P, Belghiti J. Infection of ascitic fluid by perforation of a sclerodermic colon. GastroenterolClin Biol. 1992; 16(8-9):705-7.

[15] Exadaktylos A, Papagrigoriadis S. Chronic constipation--a lethal danger in patients with systemic scleroderma. Eur J Emerg Med. 2001; 8(4):333-5.

Citation: Salem Bouomrani, Sawssan BenTeber, Ines Masmoudi, Marwa Ghribi, Multiple Perforations of the Small Intestine during Systemic Sclerosis. ARC Journal of Surgery.2019; 5(4):17-19. DOI: http://dx.doi. org/ 10.20431/2455-572X.0504004.

Copyright: (0) 2019 Authors. This is an open-access article distributed under the terms of the Creative Commons Attribution License, which permits unrestricted use, distribution, and reproduction in any medium, provided the original author and source are credited. 